\title{
A GENERAL MODEL OF SEXUAL AND NATURAL SELECTION
}

\author{
P. O'DONALD \\ Department of Zoology, University College of North Wales, Bangor
}

Received 28.xii.66

\section{INTRODUCTION}

Fisher in The Genetical Theory of Natural Selection (1930) described how mating preferences might evolve by natural selection. If mating behaviour varies among different genotypes, some individuals may have an hereditary disposition to mate with others having particular characteristics. Usually of course it is the females who choose the males and their choice is determined by the likelihood that the males' display will release their mating responses. If some females prefer to mate with those males that have characteristics advantageous in natural selection, then the genotypes that determine such matings will also be selected: the offspring will carry both the advantageous genotypes and the genotypes of the mating preference. Once the mating preference is established, it will itself add to the selective advantage of the preferred genotypes: a "runaway process" as Fisher called it develops.

In a paper in Heredity ( 1963 ) I described a mathematical model of this type of selection. In the simplest case two loci must be involved: one locus determines the preferred character and the other the mating preference. If there are only two alleles segregating at each locus, ten different genotypes can occur if the loci are linked and nine if they are not. If they are sex-linked, there are I4 possible genotypes. I derived finite difference equations giving the frequencies of the genotypes in terms of parameters describing the degree of dominance of the preferred genotypes and the recombination fractions of the loci. They are complicated, non-linear equations and cannot be solved explicitly. I could only obtain approximate solutions giving the rate of sexual selection at the start of the process and near its final equilibrium. I was unable to incorporate in the model the effects of natural selection which is what starts off the runaway process. But $I$ have now made a detailed numerical study of the equations using the Elliott 803 Computer here at the University College of North Wales and the Atlas I Computer of the Science Research Council at Chilton, Berkshire. The computers were programmed to allow for any intensity of natural selection and for variations in the size of the population.

\section{THE MATHEMATICAL MODEL}

Suppose two alleles $A$ and $B$ determine the male character and an allele $\alpha$ determines the mating preference. If the female is the heterogametic sex, females who are $X^{\alpha} Y$ mate only with $A$ males and females 
who are $X+\mathcal{Y}$ mate with $A$ and $B$ males at random. Table I shows the frequencies of the matings. Let a prime denote the frequencies of zygotes in the generation following the sexual selection of mates and let two primes denote the frequencies of the adults after the natural

TABLE I

Frequencies of matings with sex-linkage

\begin{tabular}{|c|c|c|c|c|}
\hline \multirow{2}{*}{$\begin{array}{l}\text { Genotypes and } \\
\text { their frequencies } \\
\text { in the males }\end{array}$} & \multicolumn{4}{|c|}{$\begin{array}{l}\text { Genotypes and their frequencies in the } \\
\text { females }\end{array}$} \\
\hline & $\underset{x}{X^{A \alpha} Y}$ & $\begin{array}{c}X^{B} \propto \\
y\end{array}$ & $\begin{array}{c}X^{A}+Y \\
u\end{array}$ & $\begin{array}{c}X B+Y \\
\quad v\end{array}$ \\
\hline 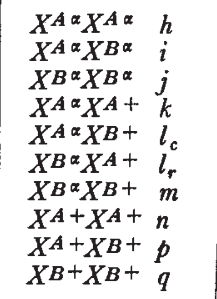 & $\begin{array}{l}h x \\
\lambda i x \\
\dddot{k} x \\
\lambda l_{c} x \\
\lambda l_{r} x \\
\ldots \\
n x \\
\lambda p x \\
\ldots\end{array}$ & $\begin{array}{l}h y \\
\lambda i y \\
\ldots \\
k y \\
\lambda l_{c y} \\
\lambda l_{r} y \\
\ldots \\
n y \\
\lambda p y \\
\ldots\end{array}$ & $\begin{array}{l}h u \\
i u \\
j u \\
k u \\
l_{c} u \\
l_{r} u \\
m u \\
n u \\
p u \\
q u\end{array}$ & $\begin{array}{l}h v \\
i v \\
j v \\
k v \\
l_{c} v \\
l_{r} v \\
m v \\
n v \\
p v \\
q v\end{array}$ \\
\hline Divisors & $F$ & $F$ & I & I \\
\hline
\end{tabular}

$F=h+k+n+\lambda i+\lambda l_{\mathrm{o}}+\lambda l_{\mathrm{r}}+\lambda p . \quad \lambda$ specifies the dominance of $A$ : dominance is complete if $\lambda=1$ and recessiveness is complete if $\lambda=0$.

selection of the zygotes. Thus $h$ is the frequency of $X^{A^{\alpha}} X^{A^{\alpha}}$ genotypes in generation $n ; h^{\prime}$ is their frequency as zygotes before natural selection in generation $n+\mathrm{I}$; and $h^{\prime \prime}$ is their frequency as adults after natural selection in generation $n+\mathrm{I}$. Let $\theta$ be the recombination fraction of the two loci $A$ and $\alpha$.

Put

$$
\begin{aligned}
& H=h+\frac{1}{2} k+\frac{1}{2} i \\
& H_{1}=h+\frac{1}{2} k+\frac{1}{2} \lambda i \\
& \mathcal{J}=j+\frac{1}{2} i+\frac{1}{2} m \\
& \mathcal{N}=n+\frac{1}{2} k+\frac{1}{2} p \\
& \mathcal{N}_{1}=n+\frac{1}{2} k+\frac{1}{2} \lambda p \\
& Q=q+\frac{1}{2} m+\frac{1}{2} p \\
& R=\frac{1}{2}(\mathrm{I}-\theta) l_{c}+\frac{1}{2} \theta l_{r} \\
& S=\frac{1}{2} \theta l_{c}+\frac{1}{2}(\mathrm{I}-\theta) l_{r},
\end{aligned}
$$

then

$$
\begin{aligned}
x^{\prime} & =(x+y)\left(H_{1}+\lambda R\right) / F+(u+v)(H+R) \\
y^{\prime} & =(x+y)\left(\frac{1}{2} \lambda i+\lambda S\right) / F+(u+v)(\mathcal{J}+S) \\
u^{\prime} & =(x+y)\left(\mathcal{N}_{1}+\lambda S\right) / F+(u+v)(\mathcal{N}+S) \\
v^{\prime} & =(x+y)\left(\frac{1}{2} \lambda p+\lambda R\right) / F+(u+v)(Q+R) \\
h^{\prime} & =x\left(H_{1}+\lambda R\right) / F \\
i^{\prime} & =x\left(\frac{1}{2} \lambda i+\lambda S\right) / F+y\left(H_{1}+\lambda R\right) / F \\
j^{\prime} & =y\left(\frac{1}{2} \lambda i+\lambda S\right) / F \\
k^{\prime} & =x\left(\mathcal{N}_{1}+\lambda S\right) / F+u(H+R)
\end{aligned}
$$




$$
\begin{aligned}
l_{c}{ }^{\prime} & =x\left(\frac{1}{2} \lambda p+\lambda R\right) / F+v(H+R) \\
l_{r}{ }^{\prime} & =y\left(\mathcal{N}_{1}+\lambda S\right) / F+u(\mathcal{J}+S) \\
m^{\prime} & =y\left(\frac{1}{2} \lambda p+\lambda R\right) / F+v(\mathcal{F}+S) \\
n^{\prime} & =u(\mathcal{N}+S) \\
p^{\prime} & =v(\mathcal{N}+S)+u(Q+R) \\
q^{\prime} & =v(Q+R)
\end{aligned}
$$

Let the selective coefficients of the genotypes $X^{A} Y$ and $X^{B} Y$ be $s_{A}$ and $s_{B}$ and of the genotypes $X^{A} X^{A}, X^{A} X^{B}$ and $X^{B} X^{B}$ let them be $s_{A A}, s_{A B}$ and $s_{B B}$.

$$
\begin{aligned}
& \text { Put } \\
& T_{f}=\left(\mathrm{I}-s_{A}\right)\left(x^{\prime}+u^{\prime}\right)+\left(\mathrm{I}-s_{B}\right)\left(y^{\prime}+v^{\prime}\right) \\
& T_{m}=\left(\mathrm{I}-s_{A A}\right)\left(h^{\prime}+k^{\prime}+n^{\prime}\right)+\left(\mathrm{I}-s_{A B}\right)\left(i^{\prime}+l_{c}{ }^{\prime}+l_{r}{ }^{\prime}+p^{\prime}\right) \\
& +\left(\mathrm{I}-s_{\text {B B }}\right)\left(j^{\prime}+m^{\prime}+q^{\prime}\right) \text {, } \\
& x^{\prime \prime}=\left(\mathrm{I}-s_{A}\right) x^{\prime} / T_{f} \\
& y^{\prime \prime}=\left(\mathrm{I}-s_{B}\right) y^{\prime} / T_{f} \\
& u^{\prime \prime}=\left(\mathrm{I}-s_{A}\right) u^{\prime} / T_{f} \\
& v^{\prime \prime}=\left(\mathrm{I}-s_{B}\right) v^{\prime} / T_{f} \\
& h^{\prime \prime}=\left(\mathrm{I}-s_{\mathrm{AA}}\right) h^{\prime} / T_{m} \\
& i^{\prime \prime}=\left(\mathrm{I}-s_{A B}\right) i^{\prime} / \mathcal{T}_{m} \\
& j^{\prime \prime}=\left(\mathrm{I}-s_{B B}\right) j^{\prime} / \mathcal{T}_{m} \\
& k^{\prime \prime}=\left(\mathrm{I}-s_{\mathrm{A} A}\right) k^{\prime} / T_{m} \\
& l_{c}^{\prime \prime}=\left(\mathrm{I}-s_{A B}\right) l_{c}^{\prime} / T_{m} \\
& l_{r}^{\prime \prime}=\left(\mathrm{I}-s_{A^{B}}\right) l_{r}^{\prime} / T m \\
& m^{\prime \prime}=\left(\mathrm{I}-s_{\mathrm{BB}}\right) m^{\prime} / \mathcal{T}_{m} \\
& n^{\prime \prime}=\left(\mathrm{I}-s_{\mathrm{A} A}\right) n^{\prime} / T_{m} \\
& p^{\prime \prime}=\left(\mathrm{I}-s_{A B}\right) p^{\prime} / T_{m} \\
& q^{\prime \prime}=\left(\mathrm{I}-s_{\mathrm{BB}}\right) q^{\prime} / \mathcal{T}_{m} .
\end{aligned}
$$

These are the steps in the calculation the computers were programmed to carry out for each succeeding generation. When the change in gene frequency of $A$ had become small enough to show that equilibrium was not far away, the computation was stopped.

As they stand, these equations are deterministic and strictly apply only to infinite populations. They will of course be accurate enough to apply to large populations. But for small populations with less than about 500 mating individuals, random drift starts to have an important effect on the results of selection. To allow for populations with different number of individuals, we first form the cumulative frequency distributions of the genotypic frequencies. Thus for the females we compute

$$
\begin{aligned}
& C_{f 1}=x^{\prime \prime} \\
& C_{f 2}=y^{\prime \prime}+C_{f 1} \\
& C_{f 3}=u^{\prime \prime}+C_{f 2} \\
& C_{f 4}=v^{\prime \prime}+C_{f 3}=\mathrm{I},
\end{aligned}
$$

and a similar distribution for the males. 
For each individual in the population, a random number, $r$, is now generated in the interval $0<r \leqslant \mathrm{I}$. I used the multiplicative congruential method which depends on the recurrence relation

$$
r_{i}=a r_{i-1}(\operatorname{modulo} m) \text {. }
$$

Hammersley and Handscombe (1964) discuss the possible values that $a$ and $m$ can take to give a satisfactory sequence of random numbers. In general, if $m=2^{k}$ and $a=3$ or 5 (modulo 8) $\mathrm{m} / 4$ random numbers will be generated before the sequence starts again. I chose $a=243$ and $m=2^{29}$ giving a sequence of $2^{27}$ numbers that were checked to ensure they were rectangularly distributed and not serially correlated. Any odd number between I and $2^{29}-$ I can be used to start the sequence of random numbers and the basic recurrence relation is then applied directly.

The random number is then compared with the cumulative frequencies of the genotypes to find the interval it lies in. Thus the frequencies of the female genotypes $X^{A^{\alpha}} \Upsilon, X^{B^{\alpha}} \Upsilon, X^{A+} \Upsilon$ and $X^{B+} \Upsilon$ are $x^{\prime \prime}, y^{\prime \prime}, u^{\prime \prime}$ and $v^{\prime \prime}$ after mating has taken place and natural selection of the offspring. Then the cumulative frequencies are

$$
\begin{aligned}
& C_{f 1}=x^{\prime \prime}, \\
& C_{f 2}=x^{\prime \prime}+y^{\prime \prime}, \\
& C_{f 3}=x^{\prime \prime}+y^{\prime \prime}+u^{\prime \prime}, \\
& C_{f 4}=x^{\prime \prime}+y^{\prime \prime}+u^{\prime \prime}+v^{\prime \prime}=\mathrm{I} .
\end{aligned}
$$

Now suppose the random number lies between $C_{f 2}$ and $\mathrm{G}_{f 3}$. It will lie in this interval with probability $u^{\prime \prime}$ and is therefore counted as a female with the genotype $X^{A+Y}$; for a female picked at random will be of this genotype with the probability $u^{\prime \prime}$. In the computer $2 \mathcal{N}$ random numbers are generated for the $\mathcal{N}$ females and $\mathcal{N}$ males in the population. The $\mathcal{N}$ numbers for the females are assigned to the four different genotypes according to which of the four intervals,

$$
0<r \leqslant C_{f 1}, C_{f 1}<r \leqslant C_{f 2}, C_{f 2}<r \leqslant C_{f 1}, C_{f 3}<r \leqslant \mathrm{I},
$$

they lie in. The proportions of the four female genotypes are therefore chosen as a multinomial sample of size $\mathcal{N}$ from a population whose expected proportions are $x^{\prime \prime}, y^{\prime \prime}, u^{\prime \prime}$ and $v^{\prime \prime}$. In a similar way, the ten male genotypes are also chosen as a multinomial sample with the expected proportions $h^{\prime \prime}, i^{\prime \prime}, j^{\prime \prime}, k^{\prime \prime}, l_{c}^{\prime \prime}, l_{r}^{\prime \prime}, m^{\prime \prime}, n^{\prime \prime}, p^{\prime \prime}$ and $q^{\prime \prime}$. This is the method Bodmer ( 1960 ) used in his simulation of the selection of homostyly in Primula vulgaris.

The new proportions of the male and female genotypes obtained in this way are now taken as the genotypic frequencies of the next generation. They determine, as shown in table $\mathrm{I}$, the new frequencies of the matings that will produce the individuals of the next generation after that. Thus in the computation, the values $x, y, u$, $v$, etc., of the previous generation are set equal to the new values and this process is repeated for each generation. It is slow if populations are large, for 
a random number must be generated for every individual in each generation. Models involving populations of finite size were programmed in Fortran for the very fast Atlas I Computer. They are of course stochastic models, for each genotypic frequency has a variance and sampling fluctuations must occur. I also studied models of infinite populations in which the expected proportions are simply taken as the observed proportions. Such models are deterministic and were programmed in Algol for the Elliott $80_{3} \mathrm{~B}$ Computer. The Fortran and Algol programs were checked against each other to ensure they were in agreement. They were also checked by hand for two generations of selection. In general models of populations with 2000 individuals gave results very close to those given by the deterministic models. In nature, of course, population sizes are often much larger than 2000 and the deterministic models should apply to them.

\section{RATES OF SEXUAL SELECTION}

In Fisher's model, the runaway process of sexual selection begins by the natural selection of the preferred character. The preferred character may be either dominant, semi-dominant or recessive and may be subject to varying intensities of natural selection. In this paper I shall deal with cases of the complete dominance or recessiveness of the preferred character and with 50 per cent. recombination between it and the mating preference. I shall consider the effects of linkage and the evolution of dominance in another paper.

When mating preferences first evolve they will inevitably be in favour of the character that has the advantage in natural selection. But of course many characters apparently evolved by sexual selection, like the spectacular plumage and display of many polygamous birds, would seem almost certainly to be disadvantageous in natural selection. Yet we can be fairly confident that sexual selection of the males caused the evolution of the character which is often developed to extreme only in polygamous species. Huxley (r938) and Wynne-Edwards (I962) have argued that group selection must be the cause of the evolution of such characters, using the hypothesis that the greater stimulation of the colony or group as a whole causes the group to produce more offspring and thus compete more strongly with other groups. The concept of group selection has been criticised on the very firm logic that it is impossible to formulate a genetical model in which it is effective. There are two main difficulties. First, groups have a much longer life than individuals so selection among groups must be much slower than selection among individuals. And, second, natural selection will still be operating within the groups and so whatever group finally emerges, natural selection will always determine its gene frequencies in the end. Nor does group selection explain the importance of polygamy in the development of extreme sexual displays; whereas it is to be expected under sexual selection which will be more effective 


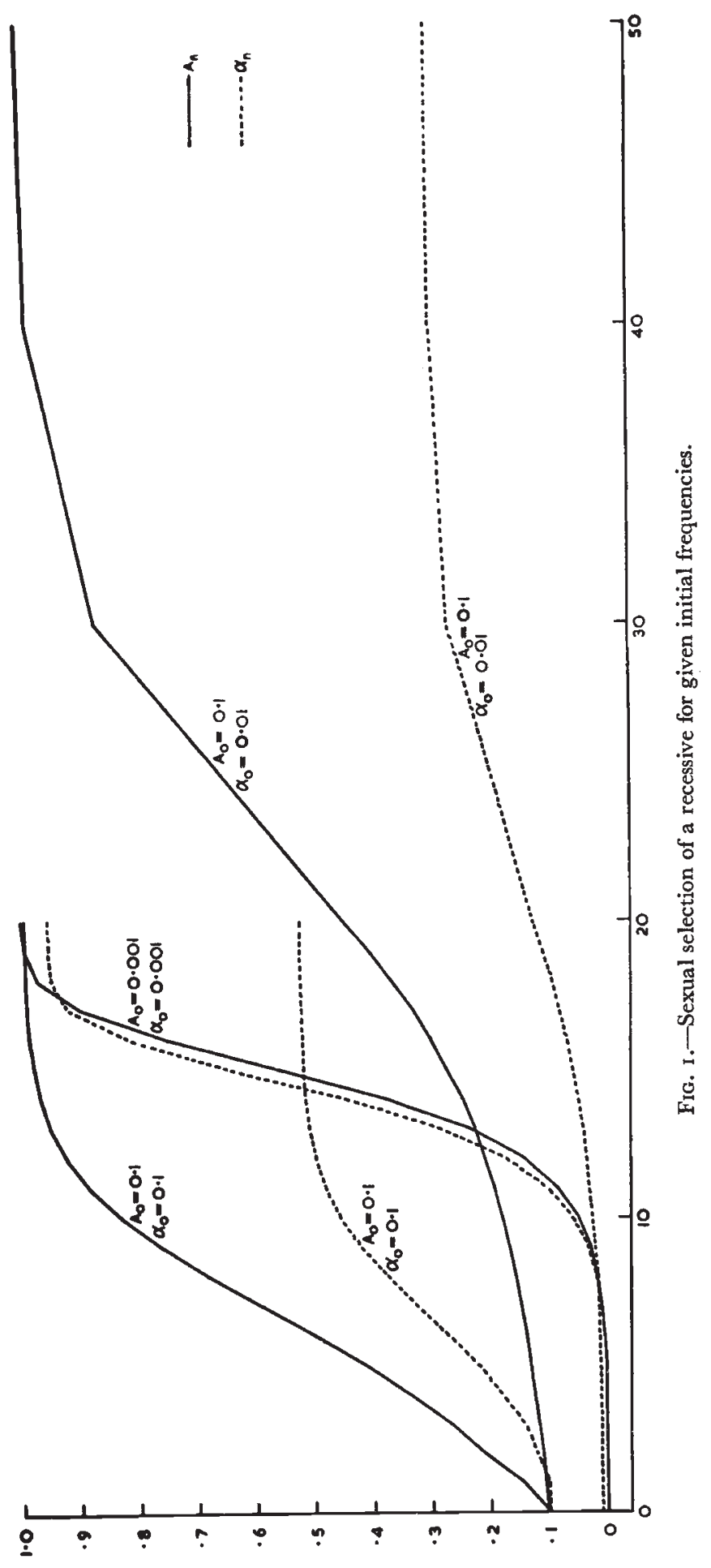


the greater the incidence and degree of the polygamy. If sexual selection caused the evolution of characters of sexual display, we must then explain how these characters can become disadvantageous and perhaps even cause the extinction of the species while still being maintained by sexual selection. There are several possible stages in this evolution. In the first stage natural selection alone favours a particular character. It may be the development of special organs for offence or defence or a conspicuous character designed for the males to lure predators away from the incubating females. Female mating preferences for the character then evolve by Fisher's process: the gene that determines the mating preference continues to increase in frequency until all the males possess the preferred character. Even so the character will vary as new mutations and new combinations of genes arise affecting it. $A$ variation that enhances it for the females will be selected, and if its enhancement by the female preference goes on, eventually, it must be assumed, it will cease to be favoured by natural selection. At this stage natural selection and sexual selection oppose each other. There are now three possibilities: either the gene enhancing the male character will continue to increase by sexual selection; or it will be eliminated by natural selection; or it will be maintained in a stable polymorphism by a balance of the opposing forces of sexual and natural selection. I have used the model to investigate these stages of natural and sexual selection.

Figure I shows the results of sexual selection for a recessive gene for particular initial frequencies of $A$ and $\alpha$, and fig. 2 shows the results for the selection of a dominant. There is no natural selection either for or against the preferred character in these two cases. The most obvious thing to notice is how much faster sexual selection is for a recessive. I had already shown in my original paper that this is to be expected. In the selection of a recessive another curious effect is to be seen. If the initial frequencies of $A$ and $\alpha$ are low-0.00 I in one of the examples shown-then although sexual selection is slow for about the first ten generations, it suddenly speeds up, becomes very fast and $A$ reaches fixation ten generations later-at the same time indeed as when $A$ and $\alpha$ start at an initial frequency of $0 \cdot 1$. Even more remarkable, from initial frequencies of $0.001, \alpha$ reaches an equilibrium frequency of $0.957 \mathrm{I}$, but from 0.1 it only reaches 0.5252 . It is perhaps more reasonable to start with $A$ more common than $\alpha$, assuming that $A$ has already to some extent spread through the population by natural selection. In this case sexual selection is somewhat slower and $\alpha$ reaches an equilibrium at 0.3190 after starting at 0.01 . Selection for a dominant is very different. It is slowest when the initial frequencies of $A$ and $\alpha$ are low: when $A$ and $\alpha$ start at 0.00 I, fixation of $A$ has not nearly been reached after Iooo generations and $\alpha$ has got to an equilibrium at 0.0150. Selection is almost as slow if $A$ starts at 0.1 and $\alpha$ starts at 0.01 . $\alpha$ then has got to equilibrium after rooo generations at a frequency of 0.0204 . $A$ is still approaching fixation. Selection of a 
P. O'DONALD

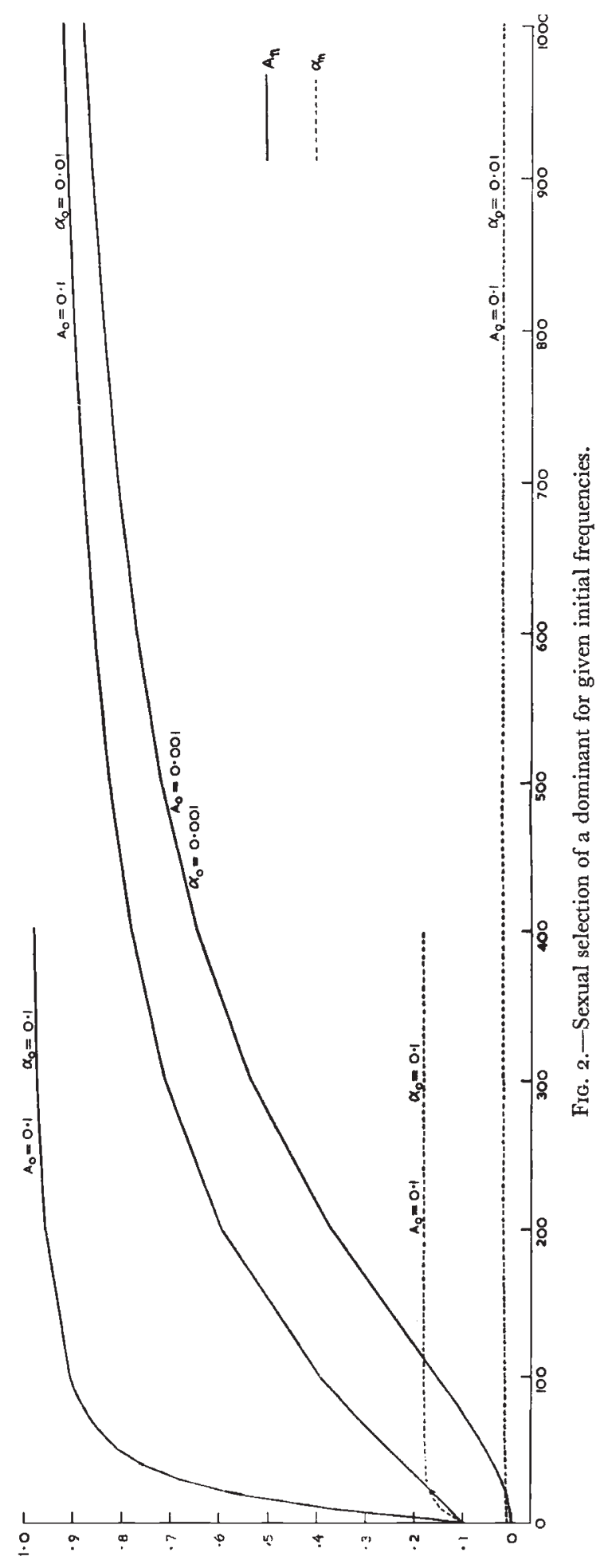


dominant is fastest if the initial frequencies are high. If $A$ and $\alpha$ start at $0 \cdot \mathrm{I}$, selection is relatively fast in the first roo generations and $A$ rises to a frequency of 0.9054 ; selection then slows down and after Iooo generations $A$ has reached a frequency of 0.99 I5. $\alpha$ reaches its equilibrium frequency of $0 \cdot$ I 8 I I after 200 generations.

These results confirm dramatically what I had suggested in my earlier paper. Sexual selection of a recessive is much faster than of a dominant because it depends on an association between the genes of the preferred character and the genes of the preference. As the preferred character is selected, so too are the genes of the preference. When a dominant is being selected, segregation in the heterozygotes must partly disperse the preference genes among the disadvantageous genotypes and sexual selection is much slower. This effect can clearly be seen if we compare the equilibrium frequencies of $\alpha$. After selection of a recessive, $\alpha$ reaches quite high frequencies - as high as about 95 per cent. if sexual selection starts when both initial frequencies are low. In the selection of a dominant, however, $\alpha$ never shows any very great increase in frequency and never gets to high frequencies.

\section{NATURAL SELECTION AND SEXUAL SELECTION}

I studied the effects of both natural and sexual selection together on two populations with different initial frequencies. Natural selection can favour either $A$ or $B$. If it favours $A$, we have a model of the first stage of sexual selection with the mating preference reinforced by natural selection. If it favours $B$, we have a model of the last stage of sexual selection with the mating preference now opposed by natural selection. Figures $3,4,5$ and 6 show the results. In all cases, the gene frequency of $A$ in females is shown. Its gene frequency in males is slightly lower, but it approaches the females frequency as equilibrium is approached. At equilibrium, as is the rule in most sex-linked systems, its frequency is the same in both the sexes. Not surprisingly, natural selection has a greater effect when the mating preference gene is at a lower frequency. It also has a much greater effect on a dominant than on a recessive. Most probably, it will be a quantitative character that is selected. If so, we may expect that at first natural selection will pick out those genes that have a dominant effect on the character. Later, when the mating preference has increased in frequency, recessive genes will be selected, for they will spread through the population so much more quickly. As the character is developed further, beyond its advantage in natural selection, the more likely it will be for recessives alone to add to its development. In fig. 6 with $A$ recessive and $\alpha$ starting at a frequency of $\mathrm{o}^{\circ} \mathrm{O}$, natural selection is not effective until there is $5^{\circ}$ per cent. selection against $A$. Even then a balanced polymorphism is established with $A$ at an equilibrium frequency of 0.686 . In fig. 5, Io per cent. natural selection eliminates the dominant $A$. If $\alpha$ starts at $\mathrm{O}^{\prime} \mathrm{I}$, fig. 4 shows a balance is not established until about 


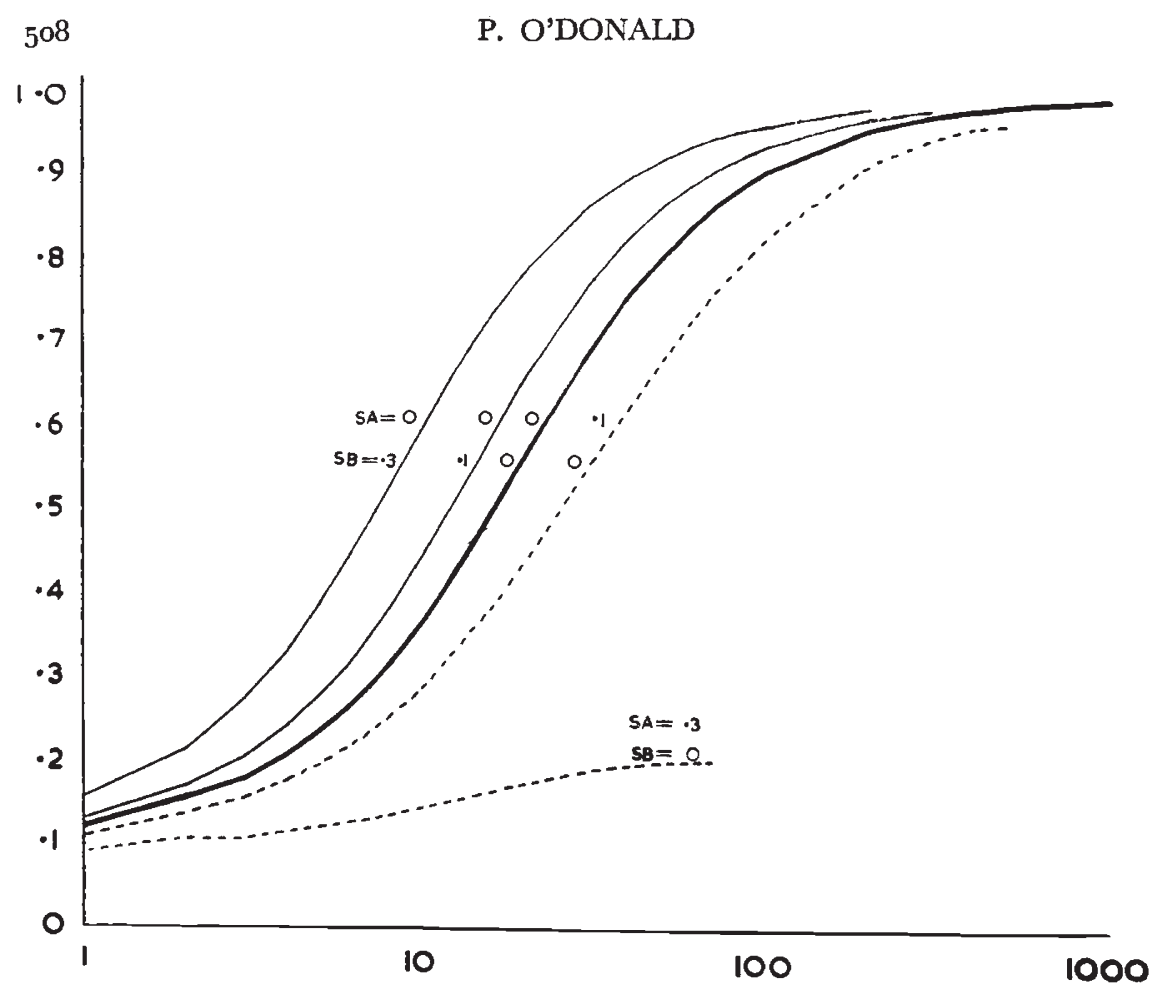

FIG. 3.-Sexual selection and natural selection of a dominant with initial frequencies $A_{0}=\alpha_{0}=0^{*} \mathrm{I}$ and selective coefficients shown either for or against $A$.

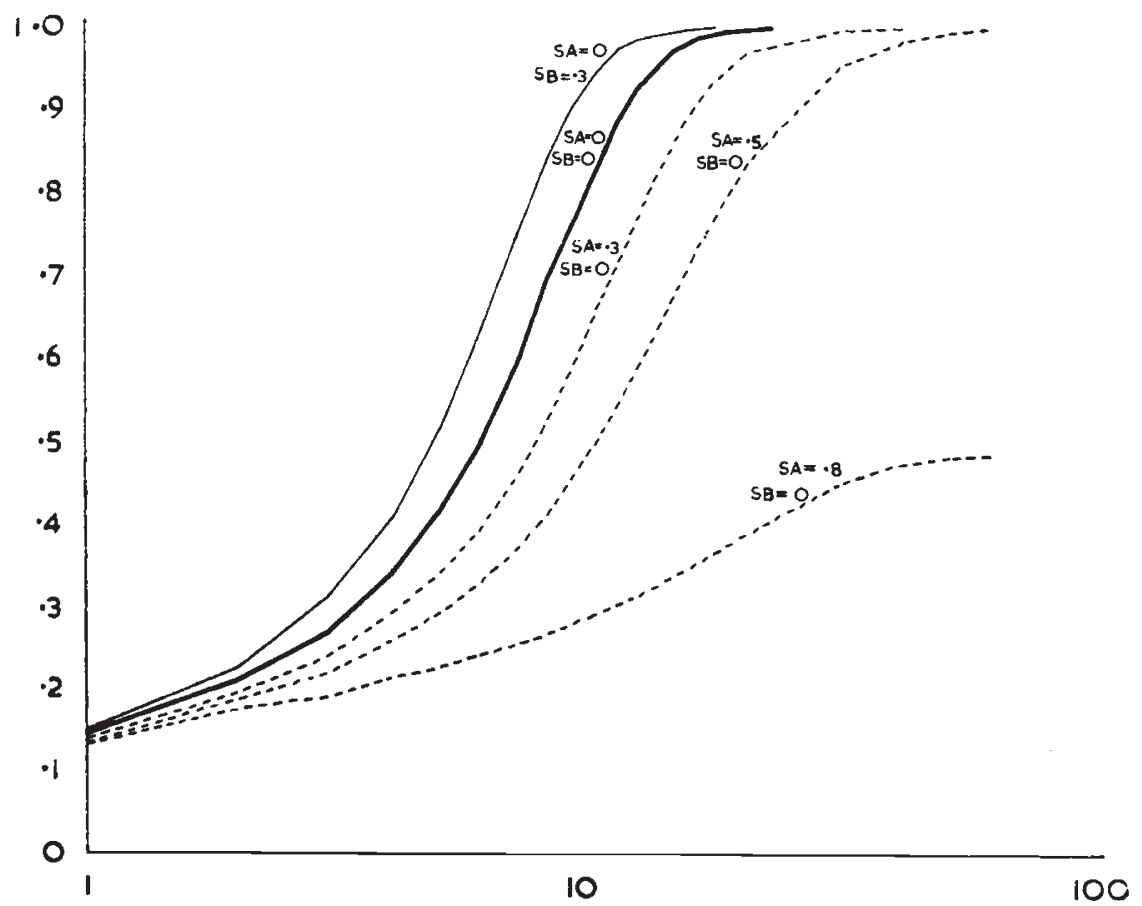

FIg. 4.-Sexual and natural selection of a recessive with initial frequencies $A_{0}=\alpha_{0}=0^{\circ}$ I and selective coefficients shown either for or against $A$. 


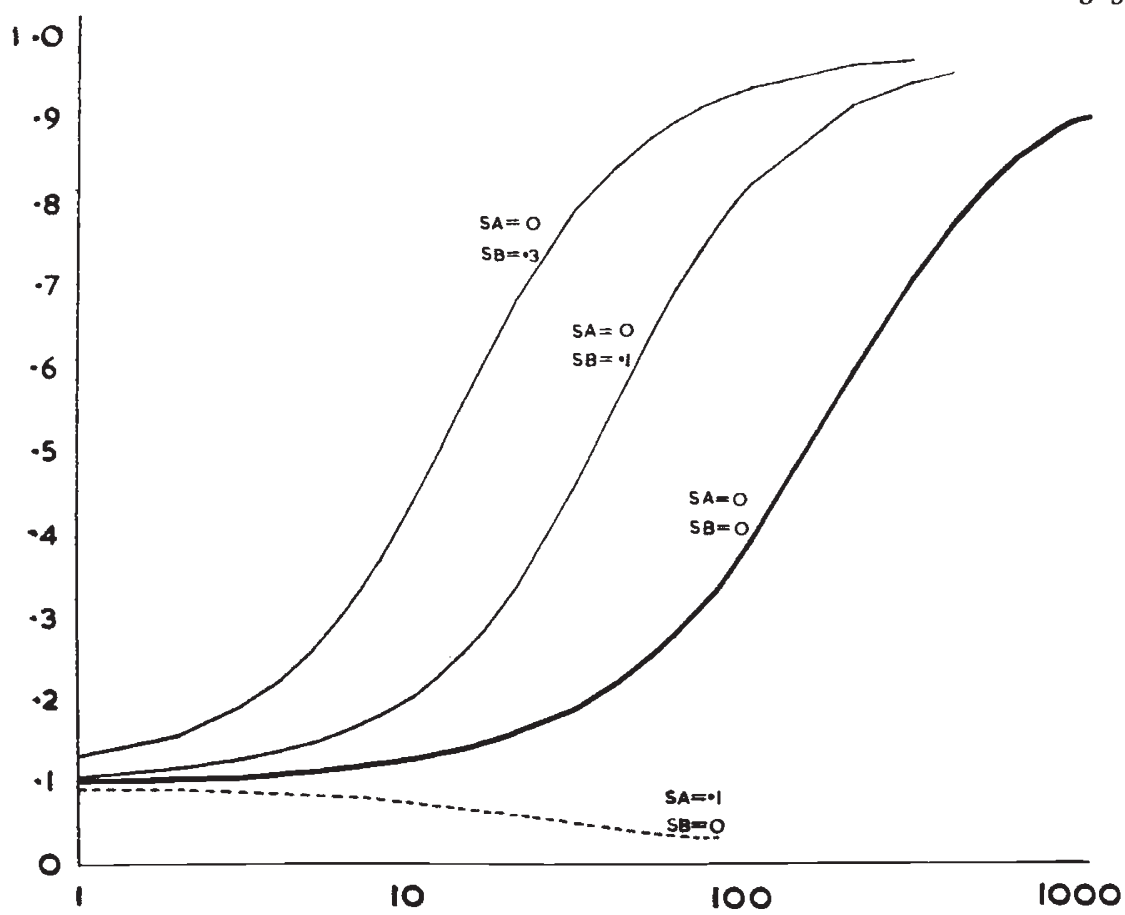

Fig. 5.-Sexual and natural selection of a dominant with initial frequencies $A_{0}=0 \cdot 1$ and $\alpha_{0}=0.01$ and selective coefficients shown either for or against $A$.

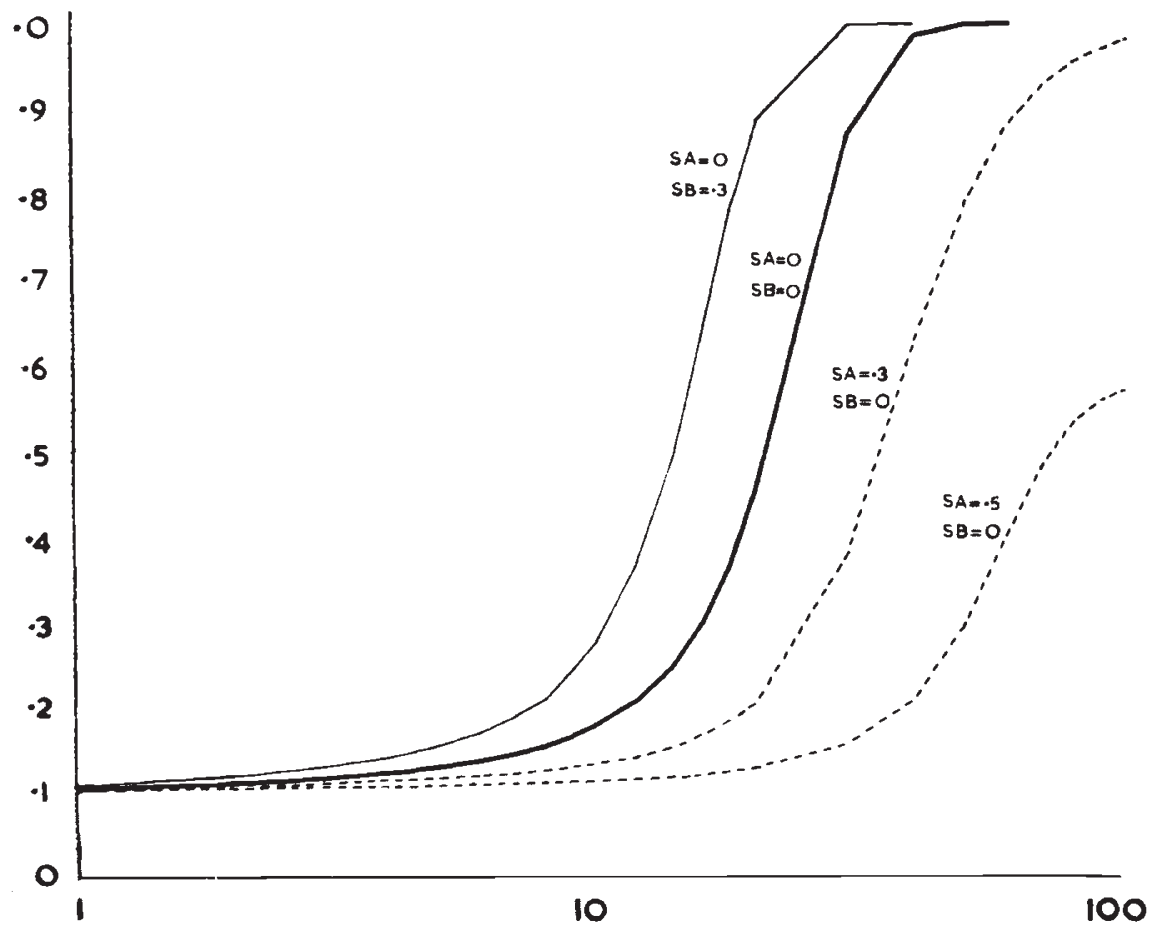

FIg. 6.-Sexual and natural selection of a recessive with initial frequencies $A_{0}=0^{\circ} \mathrm{I}$ and $\alpha_{0}=0.01$ and selective coefficients shown either for or against $A$. 
80 per cent. natural selection against a recessive or 30 per cent. natural selection against a dominant opposes the sexual selection.

Tables 2 and 3 show the equilibrium frequencies of $A$ and $\alpha$ for the various cases shown in the figures. The equilibrium frequencies

TABLE 2

Equilibrium frequencies of $\mathrm{A}$ and $\alpha$ from initial frequencies $\mathrm{A}_{0}=\alpha_{0}=0 \cdot 1$

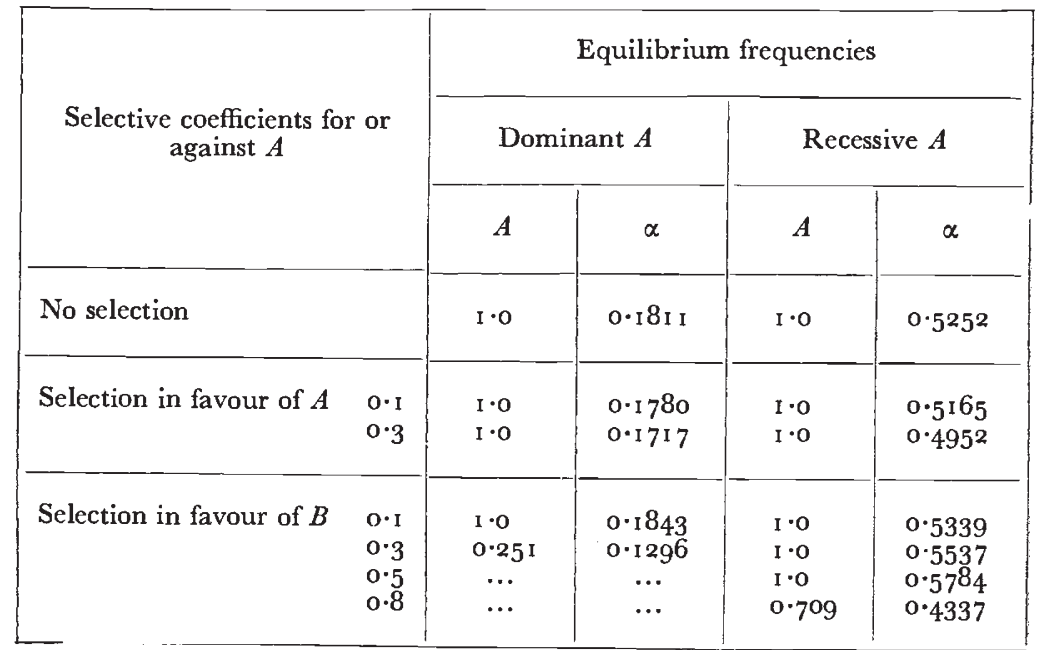

TABLE 3

Equilibrium frequencies of $\mathrm{A}$ and $\alpha$ from initial frequencies $\mathrm{A}_{0}=0 \cdot 1$ and $\alpha_{0}=0.0 \mathrm{I}$

\begin{tabular}{|c|c|c|c|c|c|}
\hline \multirow{3}{*}{\multicolumn{2}{|c|}{$\begin{array}{l}\text { Selective coefficients for or } \\
\text { against } A\end{array}$}} & \multicolumn{4}{|c|}{ Equilibrium frequencies } \\
\hline & & \multicolumn{2}{|c|}{ Dominant $A$} & \multicolumn{2}{|c|}{ Recessive $A$} \\
\hline & & $A$ & $\alpha$ & $A$ & $\alpha$ \\
\hline No selection & & $I \cdot 0$ & 0.0207 & $I \cdot O$ & $0^{\circ} 303^{1}$ \\
\hline Selection in favour of $A$ & $\begin{array}{l}0 \cdot 1 \\
0 \cdot 3\end{array}$ & $\begin{array}{l}I \cdot 0 \\
I \cdot 0\end{array}$ & $\begin{array}{l}0 \cdot 0203 \\
0 \cdot 0194\end{array}$ & $\begin{array}{l}\mathrm{I} \cdot \mathrm{O} \\
\mathrm{I} \cdot \mathrm{O}\end{array}$ & $\begin{array}{l}0 \cdot 2908 \\
0 \cdot 2597\end{array}$ \\
\hline Selection in favour of $B$ & $\begin{array}{l}0 \cdot 1 \\
0.3 \\
0.5 \\
0.8\end{array}$ & $\begin{array}{c}<0.034 \\
<0.0066 \\
\ldots \\
\ldots\end{array}$ & $\begin{array}{c}<0.0063 \\
<0.0026 \\
\ldots \\
\ldots\end{array}$ & $\begin{array}{l}\quad \ldots \\
I \cdot 0 \\
0 \cdot 686 \\
0\end{array}$ & $\begin{array}{l}\quad \ldots \\
0 \cdot 3395 \\
o \cdot 2442 \\
\text { o }\end{array}$ \\
\hline
\end{tabular}

given for $A$ are not the frequencies actually reached at equilibrium, for an infinite number of generations would be needed to reach it. They are "partial equilibria" implying that equilibrium has only been approached, not attained: a partial equilibrium is attained when 
the gene frequency from one generation to the next has changed by less than $0 \cdot 000 \mathrm{I}$. However, where the frequencies are given as $\mathrm{I} \cdot \mathrm{O}$, or complete fixation of $A$, it was possible to make the actual frequency of $A$ differ from I $\cdot$ o by any chosen small quantity simply by taking a sufficiently large number of generations. Thus

$$
\lim _{n \rightarrow \infty} A_{n}=\mathrm{I} \cdot \mathrm{O} \text {. }
$$

$\alpha$ usually reaches a steady value long before $A$ does. Once $A$ has become very abundant the selective pressure on $\alpha$ is reduced for $\alpha$ is then distributed very largely among individuals all possessing the advantageous genotype and the selective advantage of $\alpha$ depends entirely on having different proportions among advantageous and disadvantageous individuals. One odd feature of these results is to be seen in cases where natural selection is acting against $A$ but sexual selection still leads to $A$ 's fixation. The equilibrium frequency of $\alpha$ is then higher than if natural selection is in favour of $A$. Indeed, the more $A$ is favoured, the lower the equilibrium frequency of $\alpha$. This happens because the sexual selection of $A$ is slowed down by the natural selection opposing it and a longer time is available for the mating preference to evolve and become associated with the preferred genotypes. The absolute rate of selection of $\alpha$, however, is slower the greater the selection against $A$.

\section{BALANCED POLYMORPHISMS}

The results of the last section showed that for certain intensities of natural and sexual selection a stable, balanced polymorphism can be established. I have used the model to determine the range of selective coefficients that leads to this situation. I have also studied the balance of natural and sexual selection when $A$ and $\alpha$ are autosomal loci. In an autosomal model there is the additional question of the dominance of $\alpha$. I assumed that $\alpha$ was fully dominant- $\alpha \alpha$ and $\alpha+$ exercising the mating preference and ++ not doing so. This is a realistic assumption because a mating preference would be very slow to evolve if homozygotes had to appear before it were effective.

Figures 7 and 8 show the partial equilibria attained at the $A$ locus. Figure 7 shows the results for autosomal $A$ and $\alpha$ and fig. 8 the results for sex-linked $A$ and $\alpha$. In all cases selection started at an initial frequency of $\mathrm{O} \cdot \mathrm{I}$ for both $A$ and $\alpha$. The results are essentially similar for both autosomal and sex-linked cases: a balanced polymorphism is established for a recessive only when very high intensities of natural selection operate against it; but for a dominant more than about 40 per cent. selection brings almost complete fixation of $B$. Figures 9, Io, I I and I 2 show these results for dominants and recessives separately and include the equilibrium frequencies of $\alpha$ as well. Since $\alpha$ gets to equilibrium before $A$, the frequencies of $\alpha$ represent the true equilibrium frequencies. The dotted line shows the Hardy-Weinberg equilibria 


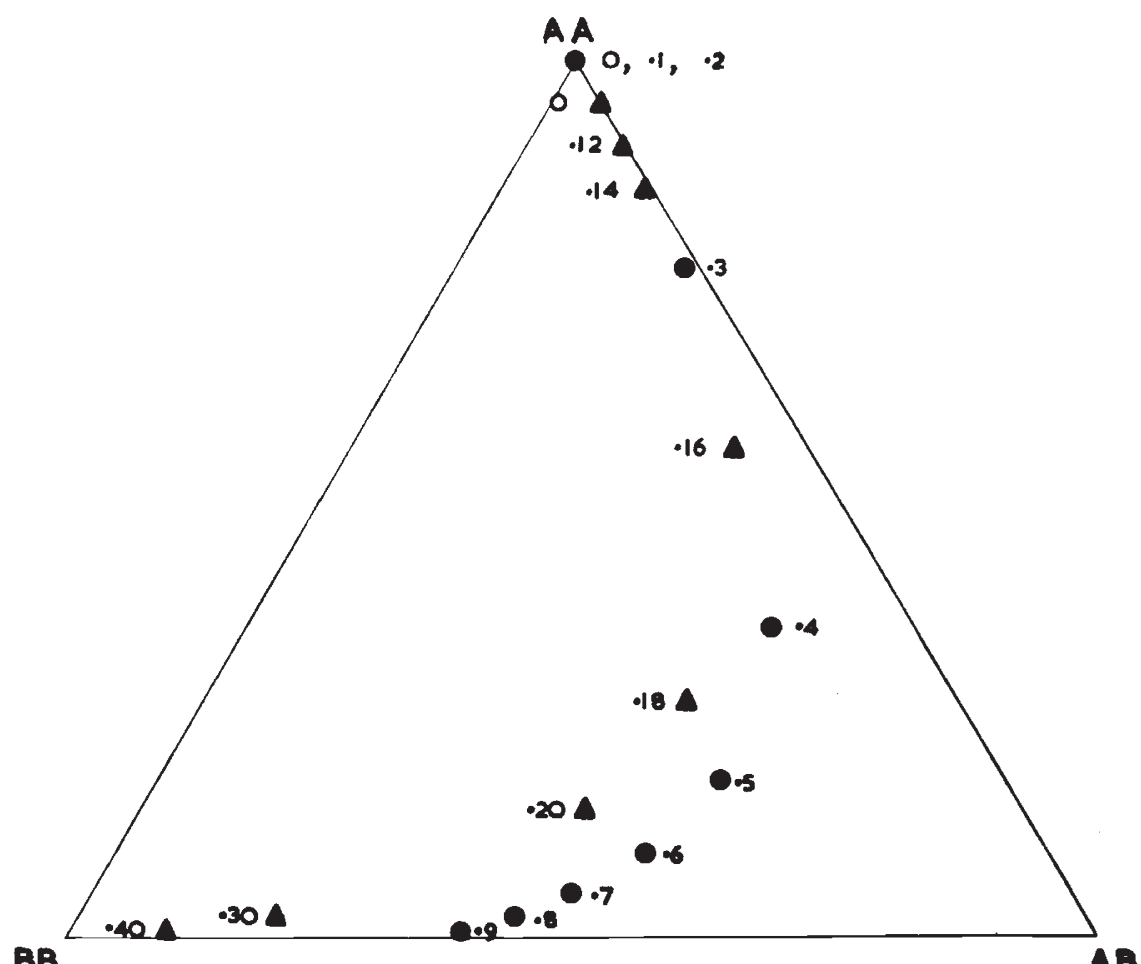

BB

Frg. 7.-Stable equilibria at an autosomal locus when natural selection opposes sexual selection. $\alpha_{0}=A_{0}=0 \cdot \mathrm{I}$. Circles are the equilibria of a recessive and triangles the equilibria of a dominant for the different coefficients of natural selection shown against the equilibria.

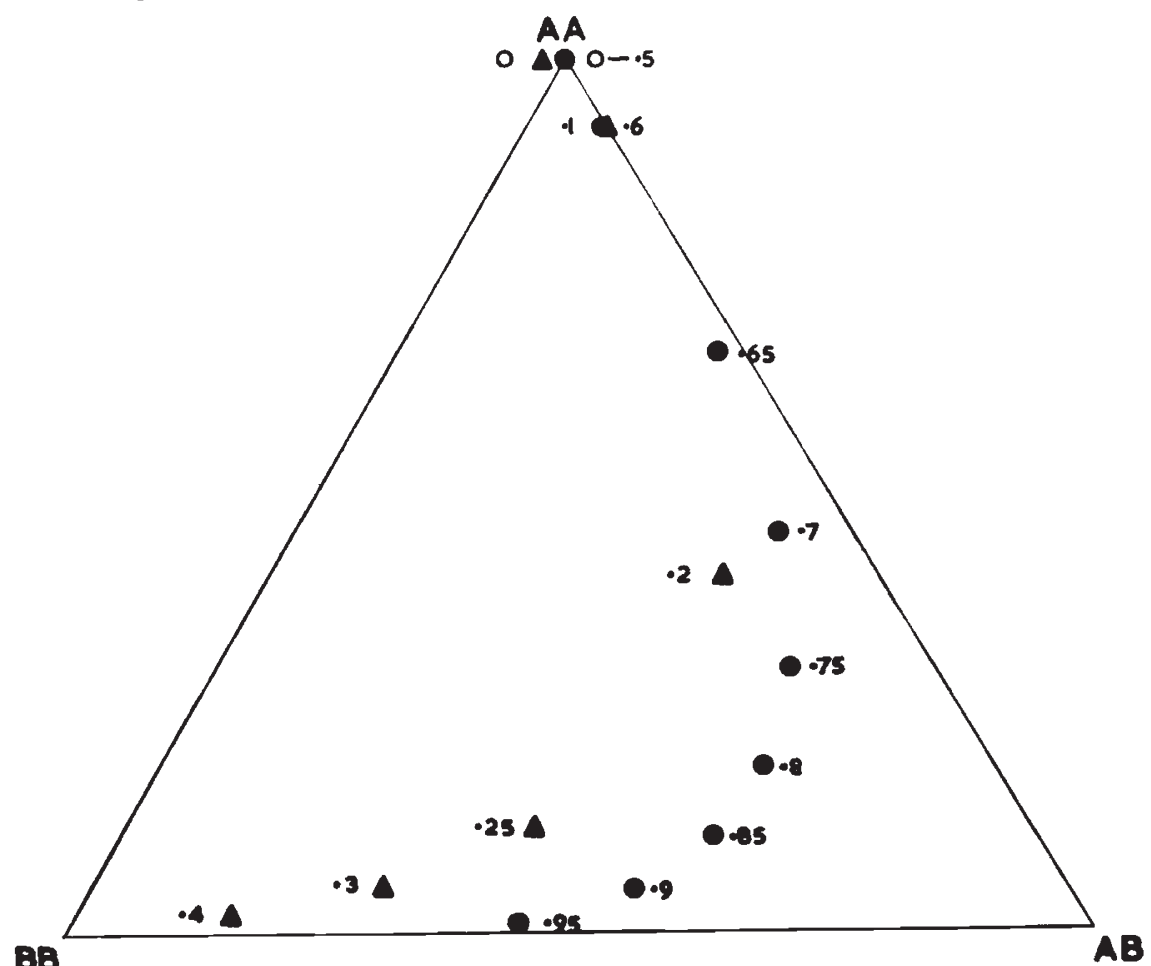

Ba

Fig. 8.-Stable equilibria at a sex-linked locus when natural selection opposes sexual selection. $\alpha_{0}=A_{0}=0_{1}$. As before, circles represent recessives and triangles dominants. The equilibria shown are the genotypic frequencies in males for comparison with the autosomal case; for there are only two genotypes in the females. 


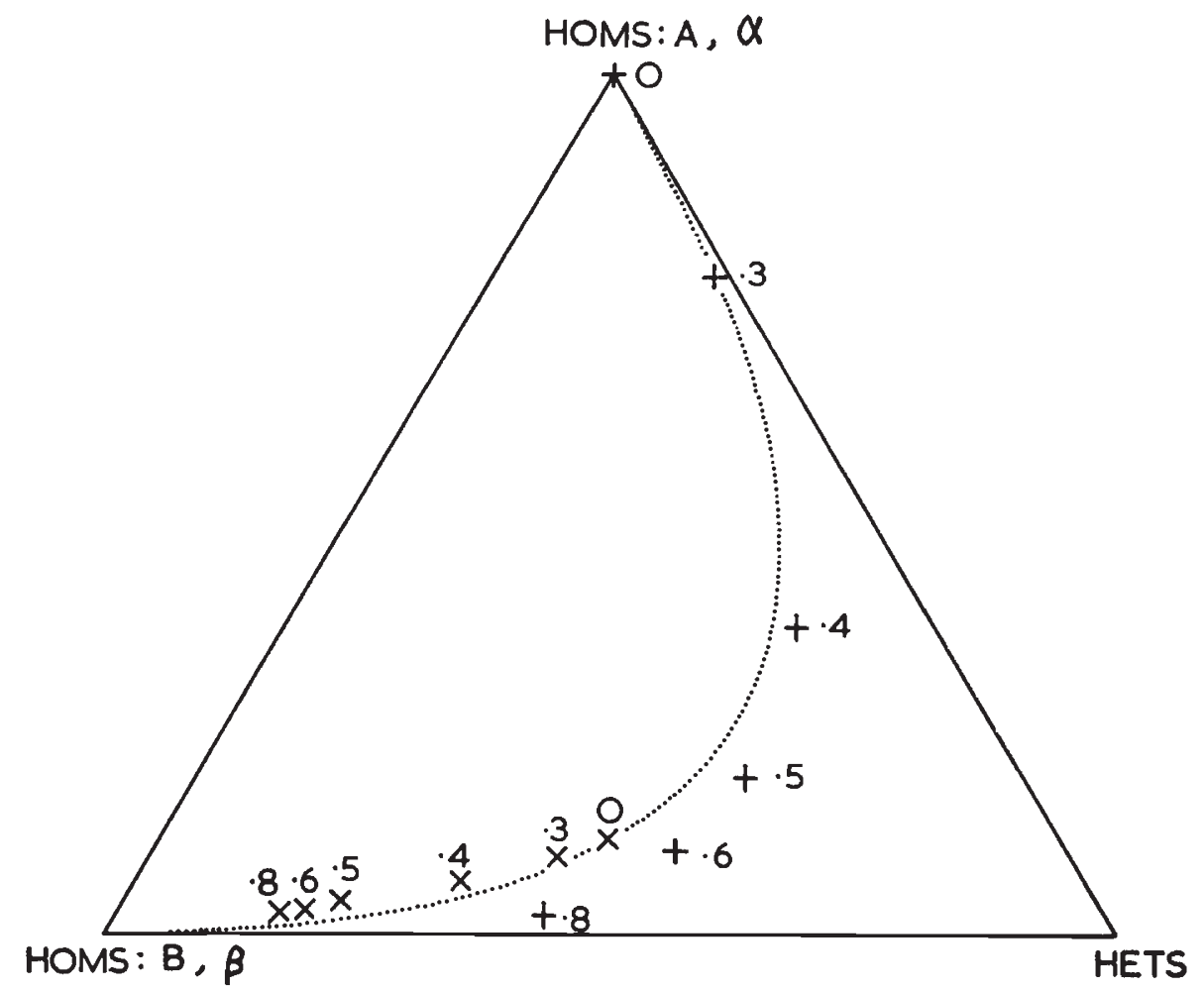

FIg. 9.-Equilibria of autosomal recessives for given selective coefficients. + represents equilibria of genotypes at the $A$ locus. $\times$ represents equilibria of genotypes at the $\alpha$ locus.

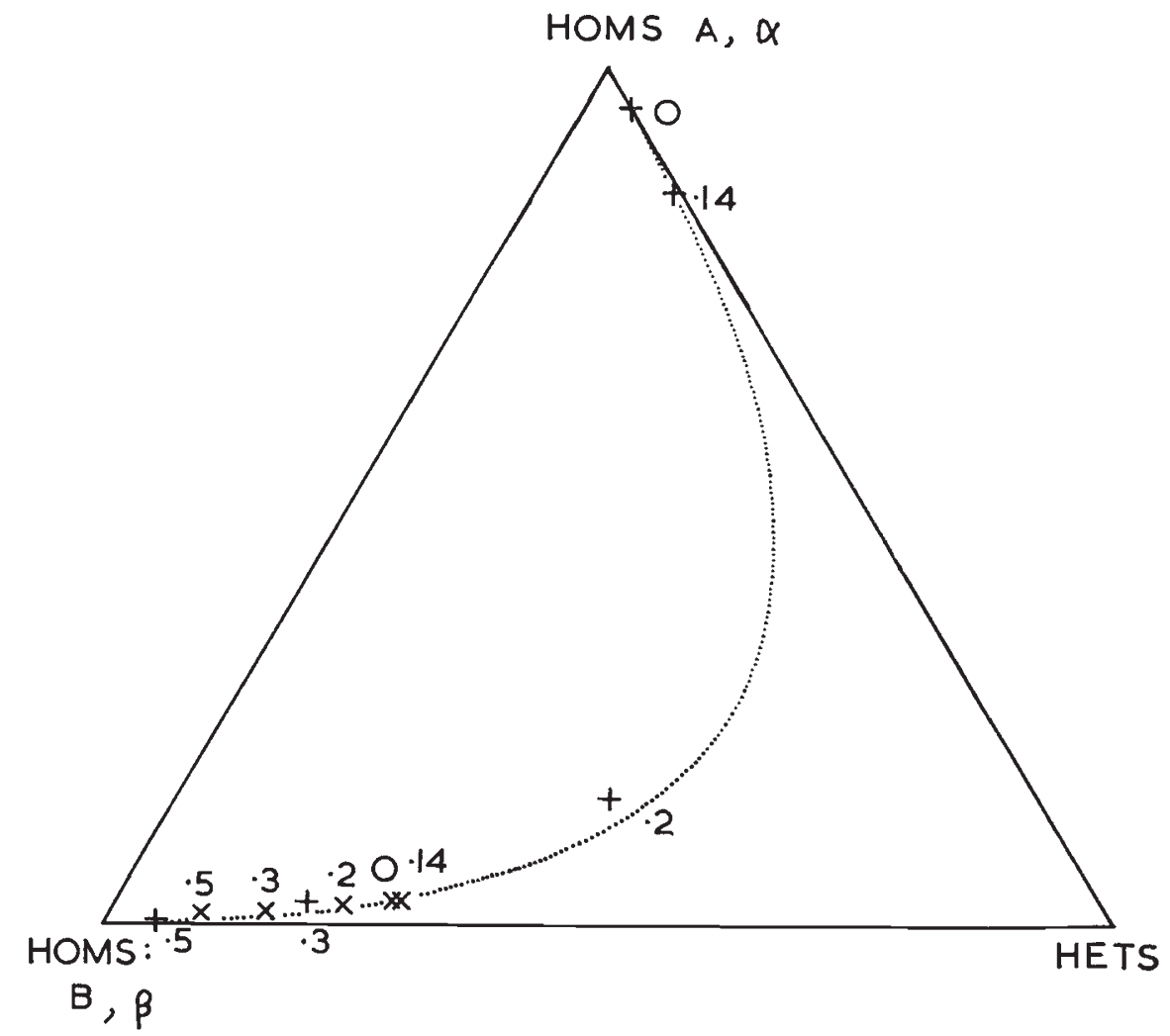

FIg. I0.-Equilibria of autosomal dominants for given selective coefficients. $2 \mathrm{~K}$ 


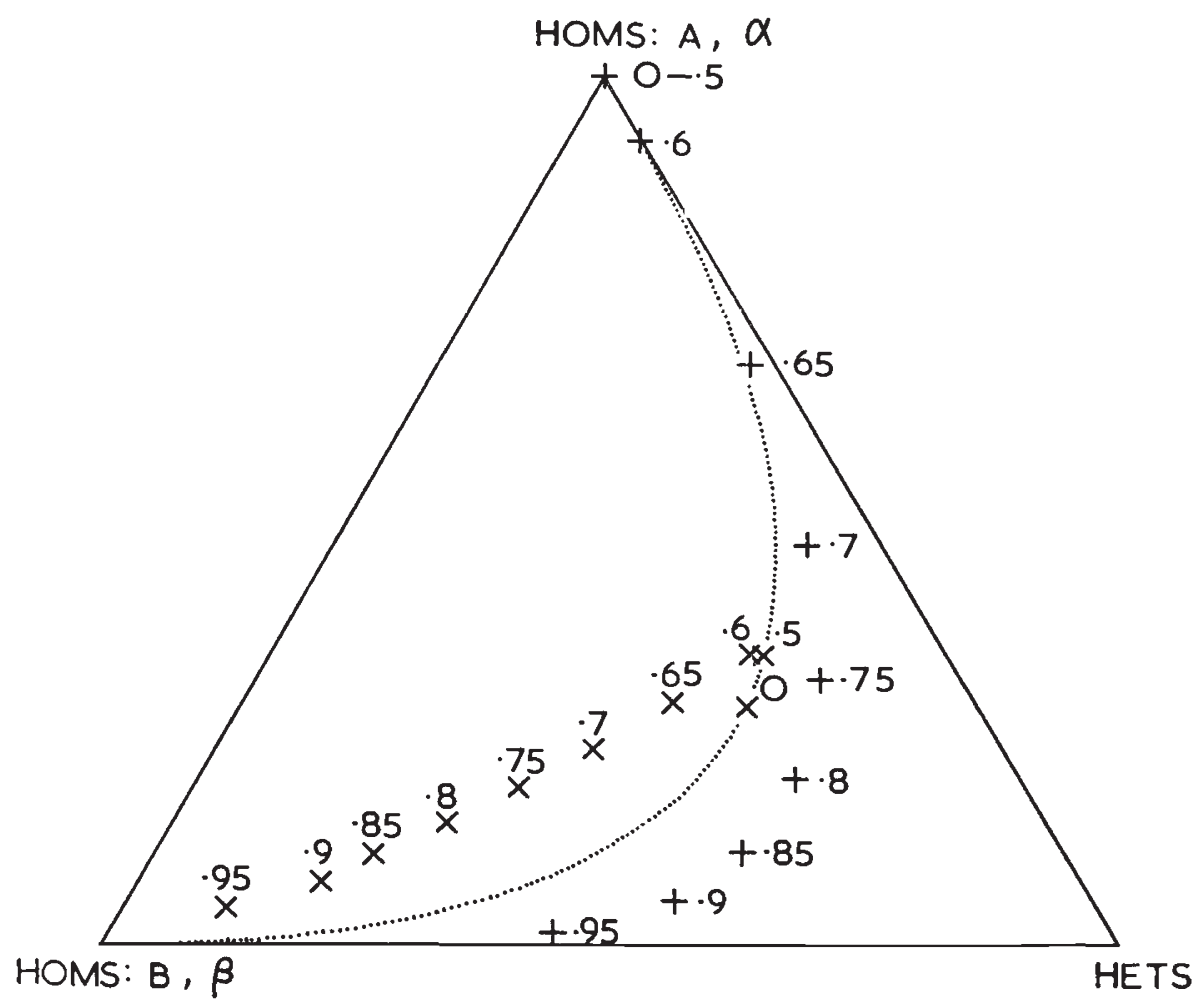

FIG. I I.-Equilibria of sex-linked recessives for given selective coefficients.

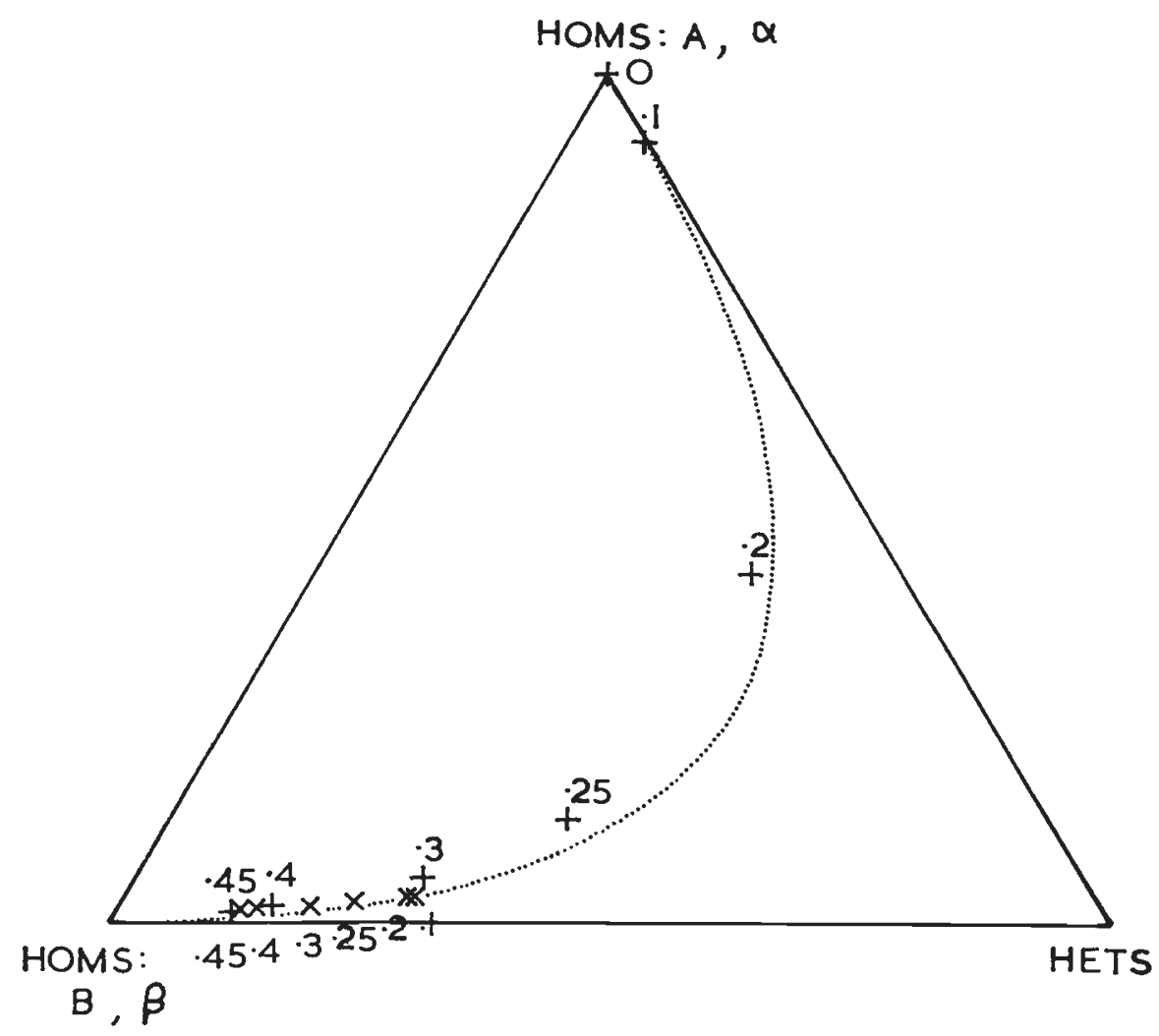

FIG. 12.-Equilibria of sex-linked dominants for given selective coefficients. 
for the whole range of gene frequencies. When recessives are selected, there is an excess of heterozygotes over the random mating proportions. A balanced polymorphism of this type could therefore easily be confused with a balanced polymorphism maintained by an heterozygote advantage, for an heterozygote advantage inevitably produces an excess of heterozygotes. When a dominant is selected, the conditions for a balanced polymorphism are more critical: in both sex-linked and autosomal models, changes in selective coefficients in the range $O \cdot I$ to

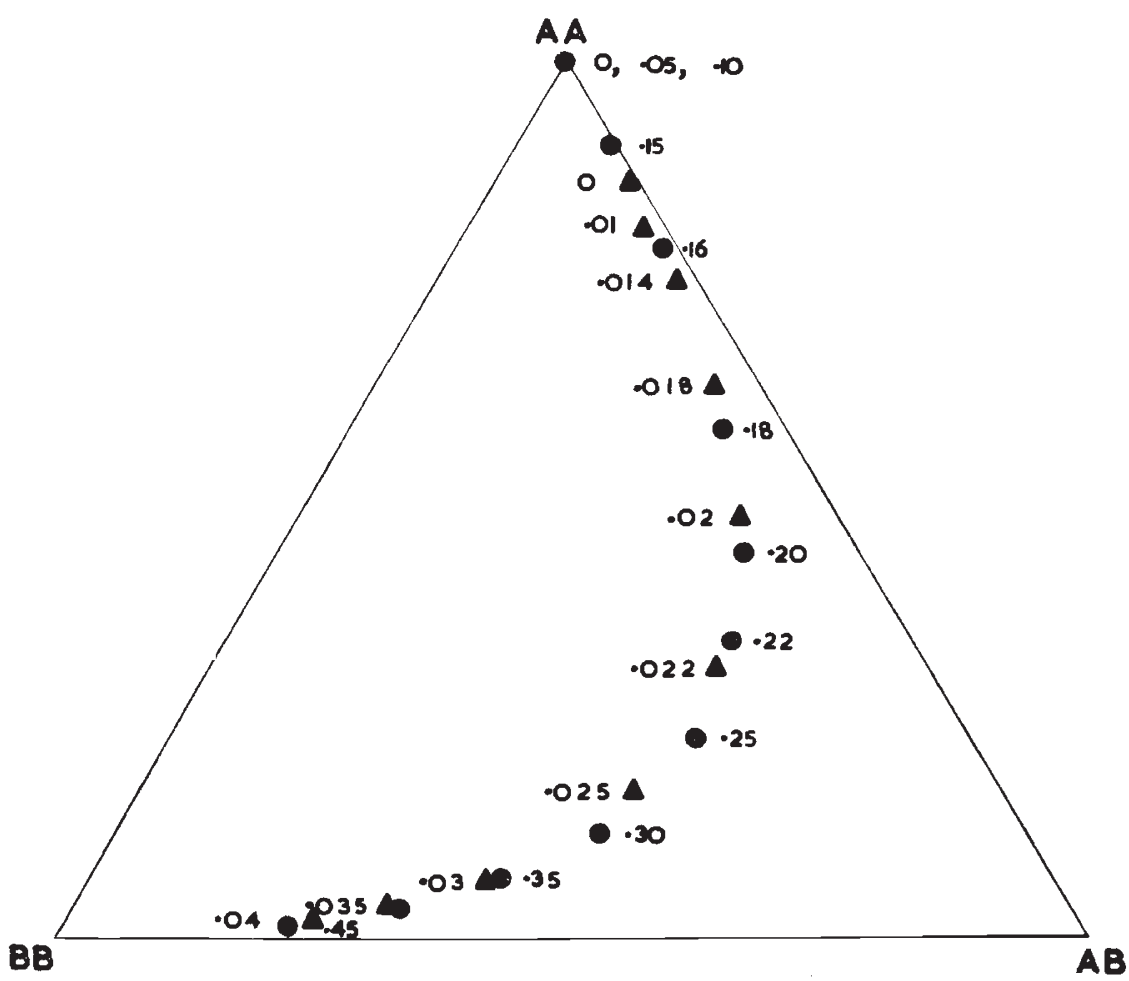

FIG. 13.-Stable equilibria at an autosomal locus when natural selection opposes sexual selection. $\alpha_{0}=0.01$ and $A_{0}=0.1$.

0.2 produce great changes in the equilibrium position. The excess of heterozygotes, too, disappears: in fact there is a slight deficiency. In the sex-linked recessive case there is a marked deficiency of $\alpha$ heterozygotes which is not shown in the other cases. This is easily explained. $X^{\propto} \Upsilon$ females mate with $X^{A} X^{A}$ males if $A$ is recessive or with $X^{A} X^{A}$ and $X^{A} X^{B}$ males if $A$ is dominant. Such preferred males also tend to carry the $\alpha$ allele. Thus the matings involving the $\alpha$ allele tend to be of two types, $X^{\alpha} Y \times X^{\alpha} X^{\alpha}$ and $X^{\alpha} Y \times X^{\alpha} X^{+}$, and the matings involving the + allele tend to be of the type $X+Y \times X+X+$. Matings are not therefore at random for the alleles $\alpha$ and + and the degree of the non-randomness determines the deficiency of the $\alpha+$ heterozygotes. Figure I 3 shows for comparison the equilibria attained at an autosomal locus 
when $\alpha$ starts at the lower initial frequency of $0 \cdot 0 \mathrm{r}$. The intensities of natural selection are still quite high for a recessive but much lower for a dominant.

\section{STOCHASTIC MODELS OF SEXUAL SELECTION}

In general the results of sexual selection in small populations depends on how many $\alpha$ alleles there are in the population. It is obvious that in a population of roo individuals with $\alpha$ at an initial frequency of $0 \cdot 0 r$ only one individual carries the allele. It is very likely to be lost by chance fluctuations and sexual selection will not operate. Only if random drift increases $\alpha$ alleles in the population will sexual selection take place and even then its intensity will vary considerably from one generation to the next as the frequency of $\alpha$ fluctuates. Everything depends on how random drift affects the numbers of $\alpha$ alleles in the first few generations. On the same principle, a large population with many $\alpha$ alleles follows closely the behaviour of an infinite population. To illustrate the course of selection for populations with few or many $\alpha$ alleles is not therefore very useful. Consider, however, a population of roo males and roo females with selection starting when the initial frequencies of $A$ and $\alpha$ are $0 \cdot \mathrm{I}$ About $20 \alpha$ alleles are present in the population. It is very unlikely for all of them to be lost by chance and when there is no natural selection for or against $A$, sexual selection proceeds at much the same rate as in an infinite population. When natural selection is opposing sexual selection, however, random drift may be important. The mating preference is determined by genes selected indirectly, like the modifiers in the evolution of dominance. They are more likely therefore to be affected by drift. Figures $I_{4}$ and I5 show this. If $A$ is recessive, 40 per cent. selection eliminates it from the population and if $A$ is dominant only 20 per cent. selection is needed to eliminate it. In neither case would $A$ be eliminated from a large population. In small populations, however, if $\alpha$ alleles are lost by random drift, natural selection alone determines the fate of $A$.

\section{SUMMARY}

I. A general mathematical model of sexual selection is set up allowing for any degree of dominance and any intensity of natural selection of the allele favoured by sexual selection. Any degree of linkage is allowed for between the locus of the allele selected and the locus that determines the female mating preference for it.

2. Sexual selection is much faster for a recessive than for a dominant. If a recessive is selected, the gene that determines the mating preference also increases rapidly and reaches a high frequency at equilibrium. If a dominant is selected, the mating preference gene only slowly increases in frequency and remains at a low frequency at equilibrium. 


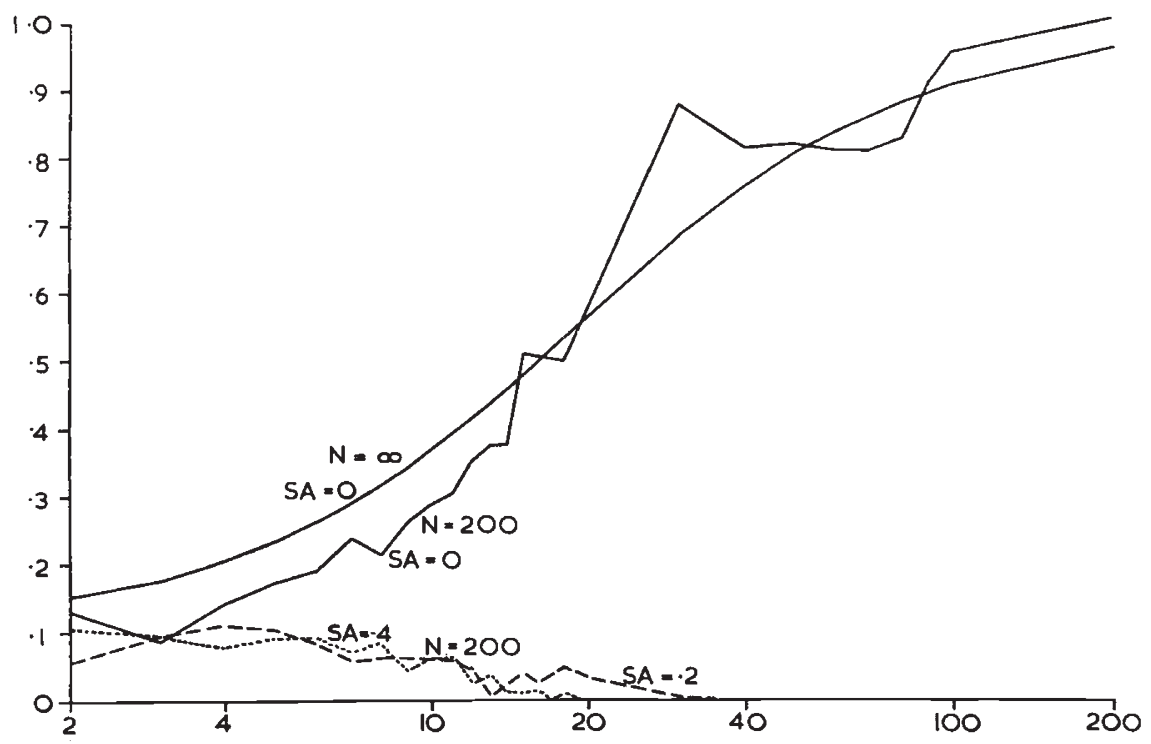

Fig. I4.-Sexual selection of a dominant in an infinite population and in populations of 200 individuals with varying coefficients of natural selection against $A$ and with no selection for or against $A$.

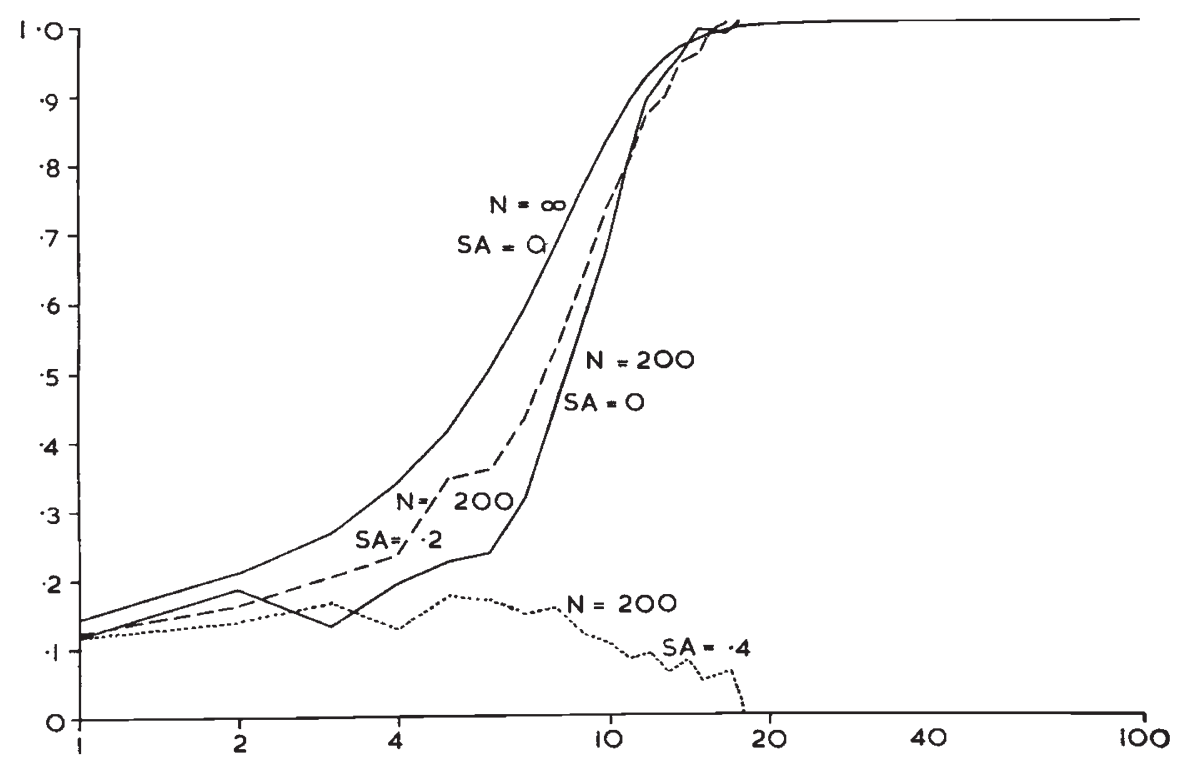

FIG. 15.-Sexual selection of a recessive in an infinite population and in populations of 200 individuals with varying coefficients of natural selection against $A$ and with no selection for or against $A$. 
3. Natural selection has more effect on the sexual selection of a dominant than on the sexual selection of a recessive. If natural selection opposes sexual selection, very high intensities of natural selection are needed to prevent the fixation of a recessive gene by sexual selection: much lower intensities of natural selection are needed to stop the sexual selection of a dominant.

4. When natural selection opposes sexual selection, a wide range of selective coefficients leads to the establishment of a stable polymorphism.

5. A stochastic model of sexual selection gives results that suggest random genetic drift may be important in populations with few mating preference genes, especially when natural selection opposes sexual selection.

\section{REFERENCES}

Bodmer, W. F. 196o. The genetics of homostyly in populations of Primula vulgaris. Phil. Trans Roy. Soc. Lond., 242, 5 I 7-549.

FISHER, R. A. 1930. The Genetical Theory of Natural Selection. Clarendon Press, Oxford.

hammersley, J. M., AND handscombe, D. c. 1964. Monte Carlo Methods. Methuen, London.

HUXLEY, J. S. 1938. The present standing of the theory of sexual selection. In de Beer, G. R., Evolution. Clarendon Press, Oxford.

o'Donald, P. I963. Sexual selection for dominant and recessive genes. Heredity, I8, $45^{\mathrm{I}-457 \text {. }}$

WYNNE-EDWARDS, v. c. 1962. Animal Dispersion in Relation to Social Behaviour. Oliver and Boyd, Edinburgh. 